\title{
Leading hand hygiene from the circle of concern to the circle of influence
}

\author{
Ng Wai Khuan \\ Infection Prevention and Control Section, Quality \& Risk Management Department, Mafraq Hospital, \\ Abu Dhabi, United Arab Emirates
}

doi: 10.3396/ijic.v8i2.016.12

\begin{abstract}
The rate of healthcare-associated infection (HAI) in Mafraq hospital was 1.6 per 1000 patient days and it was higher than the 2009 benchmark from Centers for Disease Control \& Prevention (CDC), which is 0.4 per 1000 patient days. The infection preventionists and marketing team worked together with the executive team to brainstorm and develop interventions which reduce barriers to improve hand hygiene compliance. The massive hand hygiene campaigns phase 1 and 2 were held in July and October 2010. After 15 months, the hand hygiene compliance rate increased to $86 \%$. As hand hygiene compliance improved, it was noted that, during the same time, the healthcare-associated infection rates decreased to below 0.4 per 1000 patient days in April, May and June 2011. For July 2011, healthcare-associated infection rates increased to 0.6 due to increased patient co morbidity even though hand hygiene compliance rates increased to $86 \%$. However, patient co morbidity is a non-modifiable risk factor for healthcare-associated infections.
\end{abstract}

The evidence from the hand hygiene campaigns launched in Mafraq Hospital showed a decrease in healthcareassociated infections as the compliance increased. Mafraq hospital has a significant increase of hand hygiene compliance by $64 \%$ in 15 months period and therefore, it can be concluded that hand hygiene compliance can be significantly improved through 'Hand Hygiene' campaigns. However, a limitation of this study is that since there was no result shown about patient co morbidity in the period before the hand hygiene campaigns, it is not known if the decrease of healthcare-associated infections were because of the campaigns or due to the difference in patient population.

\section{Corresponding author}

$\mathrm{Ng}$ Wai Khuan

Infection Prevention and Control Section, Quality \& Risk Management Department, Mafraq Hospital, P.O.

Box 2951, Abu Dhabi, United Arab Emirates | Tel: 00971505825689

Email: nkhuan@mafraqhospital.ae 


\section{Key words}

CROSS INFECTION; HANDWASHING; INSERVICE TRAINING; HEALTH PERSONNEL - education; GUIDELINE ADHERENCE

\section{Introduction}

Healthcare associated infections are an important cause of morbidity and mortality among hospitalized patients worldwide. The World Health Organization [WHO] conducted a prevalence survey revealing that, over 1.4 million people world-wide suffer from infectious complications associated with health care. ${ }^{1}$

Transmission of healthcare associated pathogens from one patient to another most often occurs via the contaminated hands of health care workers. Nowadays, hand hygiene is a critical, least expensive and central component of patient and healthcare workers safety. ${ }^{2}$ However, compliance with hand hygiene has been unacceptably poor, with mean baseline rates ranging from $5 \%$ to $81 \%$, with an overall average of about $40 \%{ }^{3}$

The following paper is going to present a successful cultural and behavioural transformation at Mafraq Hospital which resulted in improvement of hand hygiene practices.

\section{Background}

Mafraq Hospital is a 450 bedded tertiary care hospital. In April 2010, the rate of healthcare-associated infection was 1.6 per 1000 patient days while Centers for Disease Control \& Prevention (CDC) 2009 benchmark is 0.4 per 1000 patient days. ${ }^{4}$ This high rate of healthcare associated infections (an outcome indicator) was paralleled by a poor compliance in hand hygiene by healthcare professionals evidenced by a rate that reached 22\% in April 2010.

These two indicators signified an urgent need for action especially that one of the indicators was a process indicator and the second one was an outcome indicator. The infection preventionists believed that if hand hygiene improved, it would have a positive impact on the healthcare associated infections rates. It was very clear that we had a problem with hand hygiene, which is considered the single most important part of preventing the spread of infection. ${ }^{5}$ This was considered an opportunity for improvement, but also a serious threat to patient safety in our organization. The Centers for Disease Control and Prevention (CDC) and Healthcare Infection Control Practices Advisory Committee (HICPAC) published a Guideline for Hand Hygiene in Health care Settings in year 2002. Mafraq Hospital responded by changing written policies and procedures as well as providing recommended products. However, this induces nonvoluntary behavior through the threat of punishment for noncompliance (e.g., termination of employment for policy violation) and reduces the health care workers' freedom to choose compliance. ${ }^{6}$ This has also resulted health care workers complying with the recommendations only because they are 'forced' and scared of losing their jobs.

\section{Methods}

Health care workers have their own reasons for not complying with infection prevention and control practices. Though we usually presume that health care workers should comply with infection prevention and control practices due to their professional ethics or sense of philanthropy, they may in fact be motivated by self-interest.

A brief educational campaign or the existence of policy is usually insufficient. Product promotion, including mass media (e.g., poster, computer screen-saver or verbal reinforcement from opinion leaders), special events (e.g., contest) or interpersonal communication (e.g., recognition award, gift or certificates when caught using hand rub), are important to enhance the benefits of a desired behaviour. ${ }^{78}$

To prevent "blaming \& shaming", the infection preventionists also tried to move further than what seems to be the symptoms of a bad system. To carry out a systems analysis, the infection preventionists used information from day to day interaction with the staff and direct observation and previous incidents reported by the healthcare workers. Their daily active process surveillance gave them deep insight into the activities at the front line. A brainstorming 


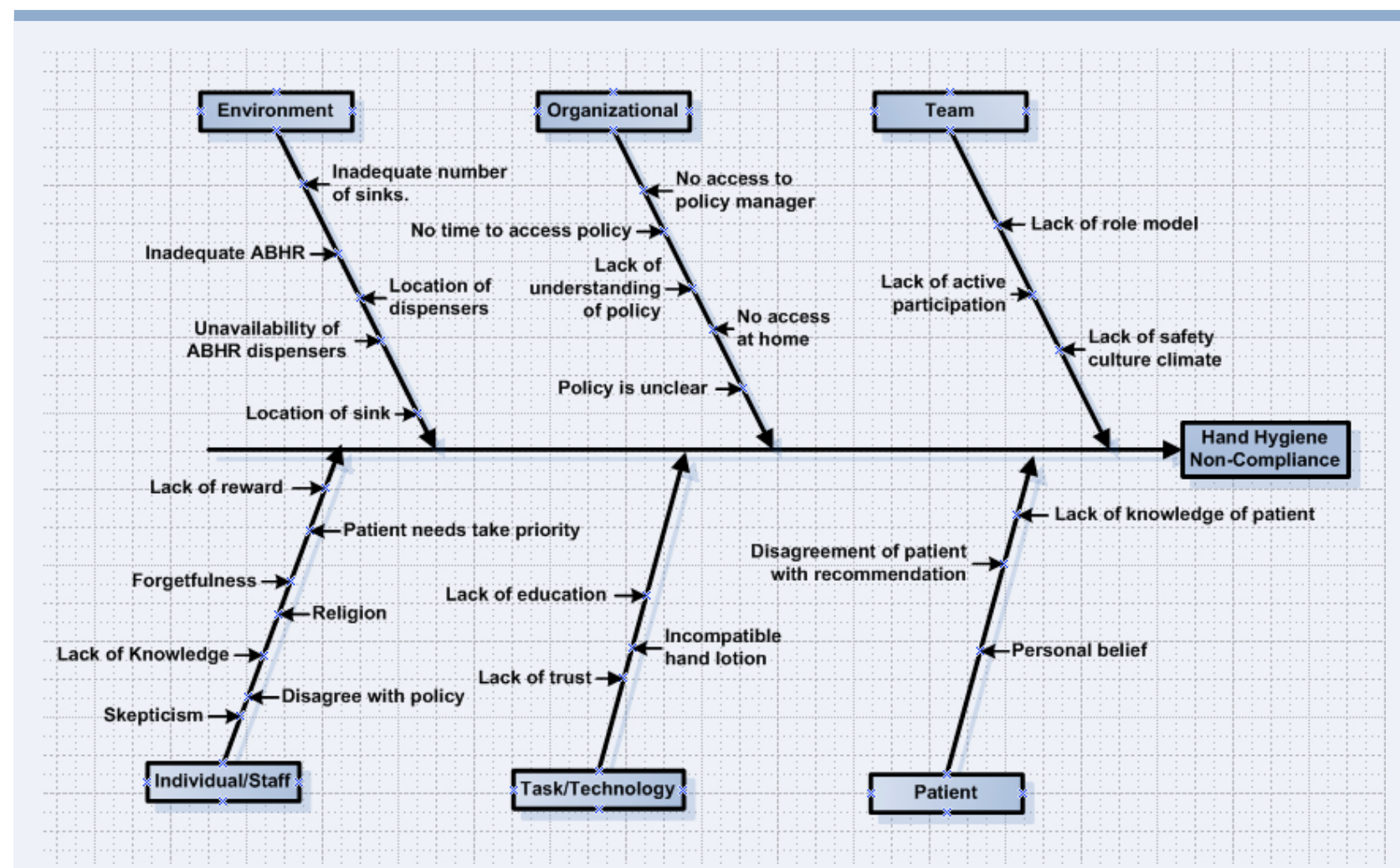

Figure 1. Ishikawa Diagram (Causes of Hand Hygiene Non-Compliance)

session of the root causes was held by the infection preventionists, marketing team and executive team. The information collected was drafted on an Ishikawa diagram (see Figure 1).

Hand hygiene compliance will not continue for long time if alcohol based hand rub is introduced without other interventions that modify health care worker behavior. ${ }^{9}$ The problem seemed indeed behavioural. Best practice and review of the literatures were methods used to make decisions and choose solutions. Senior management team was also consulted about the feasibility of solutions, face to face informal interviews with the healthcare workers and staff meetings were another opportunities to share information and collect their input. With the high rate of healthcare associated infection presented earlier and the low rates of hand hygiene compliance, the team was easily able to justify their solutions and create a sense of urgency. In addition to the data from the audits and the surveillance that was used, the team also presented a force-field analysis (see Figure 2) to illustrate the potential driving forces as opposed to the restraining ones.
Apart from the literature review that was done, the infection preventionists, marketing and executive teams also depended on their innovative thinking. The stakeholders were involved all the time by infection preventionists. This happened through feedback about the progress to the infection prevention \& control committee and to the senior management team. The project was brought to the leadership council which included representatives from across the hospital.

A proposal was submitted to senior management with the recommended solutions and implementation plan. The final solutions and plan were reviewed against the root causes. The tangible benefit expected from implementation was that hand hygiene compliance will improve and healthcare-associated infections will reduce after the project implementation, while the intangible benefit of patient satisfaction will improve.

Finally, the facility decided to adopt an aggressive 'Hand Hygiene' campaign integrating multiple changes and approaches to prevent issues of poor hand hygiene compliance. The interventions that were 
implemented were designed to break down barriers and enhance compliance. All following proposed ideas or interventions were carried out:

- Disseminated hospital wide hand hygiene random audit result and alerted the leaders and key stakeholders of the low hand hygiene compliance rate in Mafraq Hospital. ${ }^{10,11}$

- Hand hygiene campaign and creation of hand shape mascot.

- WHO 5 moments for hand hygiene were printed on leaflets, posters and small hand held gadgets (i.e., hand shape fan).

- Hand hygiene reminders 'Please Wash Your Hands' were printed on bright colour door hangers (i.e., orange, red, purple and blue).

- Alcohol-based hand rub dispensers were mounted near all elevators and Time \& Attendance machines. [Consuming time to perform hand hygiene during a hectic work shift is at a high price of hand hygiene.
Oppositely, the lower time expenditure required for use of alcohol-based hand rub lowers the hand hygiene price. Thus, alcohol hand rub should be readily accessible in convenient places $\left.{ }^{67}\right]$

- Infection prevention \& control link program was expanded throughout the organization.

- Purchased hand scanner. [The use of biosimulators and visual training is an important new approach for learning in the health care setting, which allows health care workers to see the impact of disease transmission compared to traditional didactic education. $\left.{ }^{7,12}\right]$

- Education on importance \& proper techniques of hand hygiene were reinforced through meeting and training.

- Hand hygiene random audits by units and specialties with immediate feedback to stakeholders were performed by infection preventionist and link practitioners on regular (i.e., monthly) basis. ${ }^{13}$

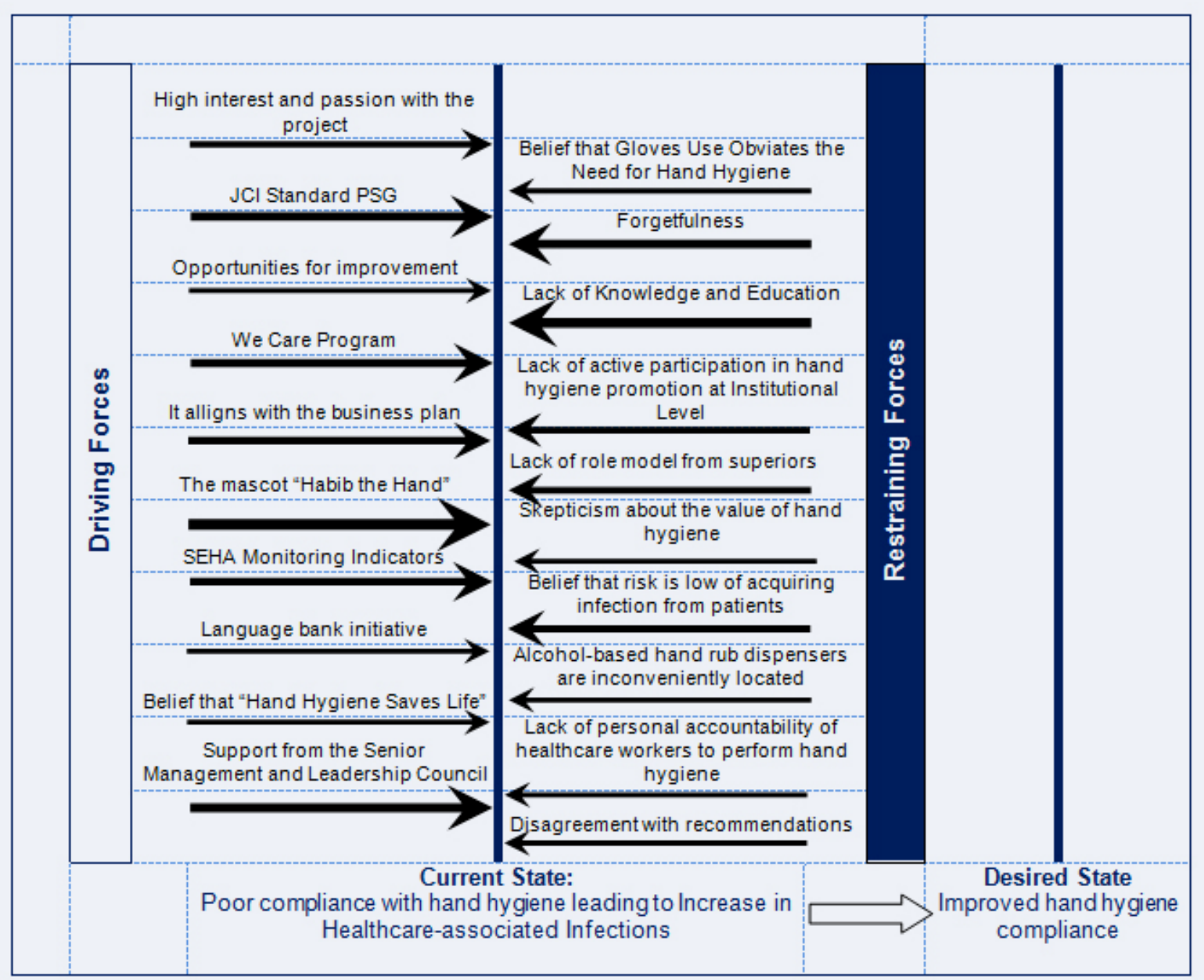

Figure 2. Force-Field Analysis

JCI Standard PSG - Joint Commission International standard for Patient Safety Goals

SEHA Monitoring Indicators - Abu Dhabi Health Services Company Monitoring Indicators 


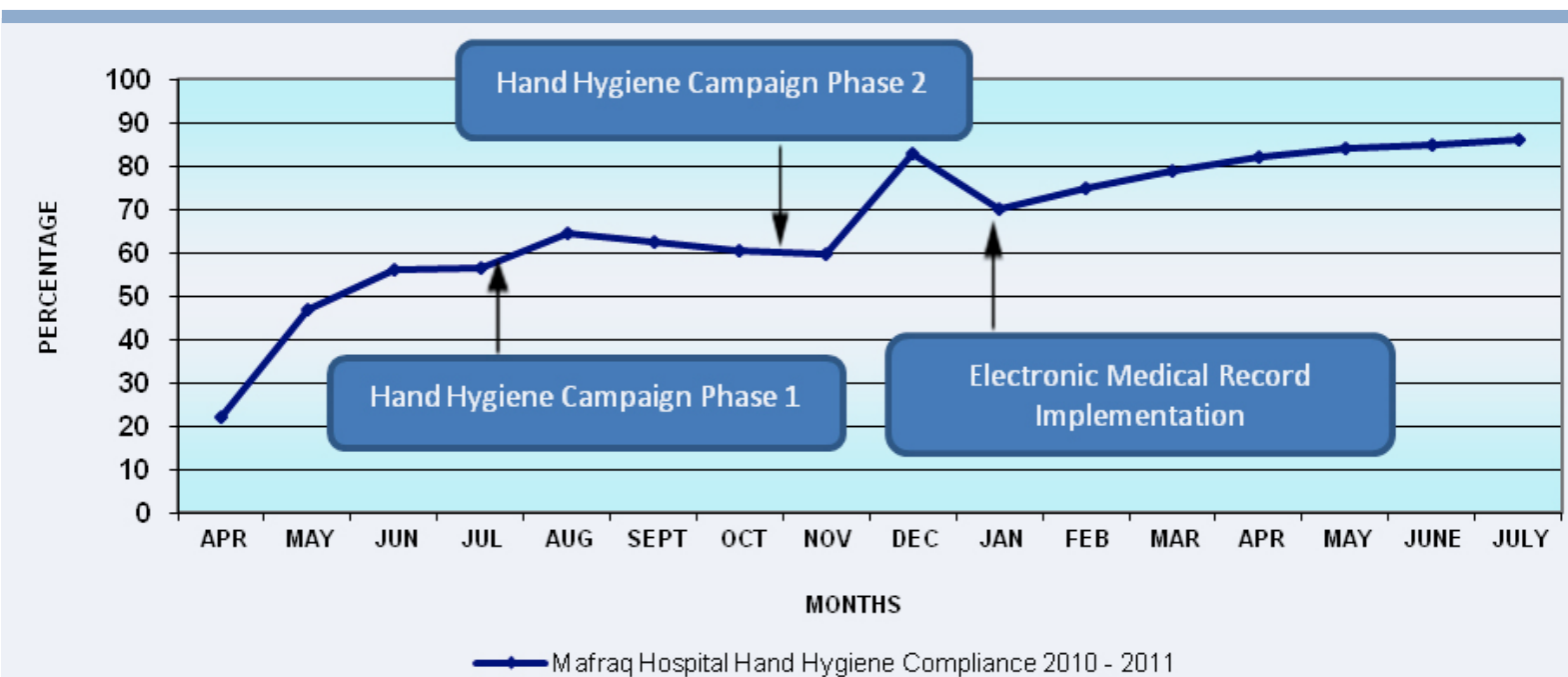

Figure 3. Hospital Wide Hand Hygiene Compliance Rate April 2010 - July 2011

\section{Results}

After 15 months, the hand hygiene compliance rate increased to $86 \%$ in July 2011. As reflected in Figure 3 , the compliance rate increased to $64.6 \%$ in August 2010 after the launch of hand hygiene campaign phase 1 but it decreased to $60.7 \%$ in October 2010 until the launch of hand hygiene campaign phase 2 .

After the phase 2 campaign, the compliance rate has significantly increased to $83.1 \%$ in December 2011. However a month later (January 2011), the rate has decreased to $70 \%$ possibly due to the stress from getting adapted to the new electronic medical record (EMR) system but it has increased in subsequent months. This was possibly due to weekly hand hygiene reinforcement during meeting and training, monthly random audit and consistent feedback.

As hand hygiene compliance improved, it was noted that, during the same time, the healthcare-associated infection rates decreased to and below 0.4 per 1000 patient days in April, May and June 2011. Figure 4 represents the hand hygiene compliance rate in relation to the healthcareassociated infection rates. However with 3 additional cases of central-line associated bloodstream infection in July 2011, the healthcare-associated infection rates increased to 0.6. The significant increase was possibly due to increased patient co morbidity (i.e., 1 case of low birth weight neonate on total parenteral nutrition for more than 2 weeks; 2 cases of patients with cancer who were on chemotherapy).

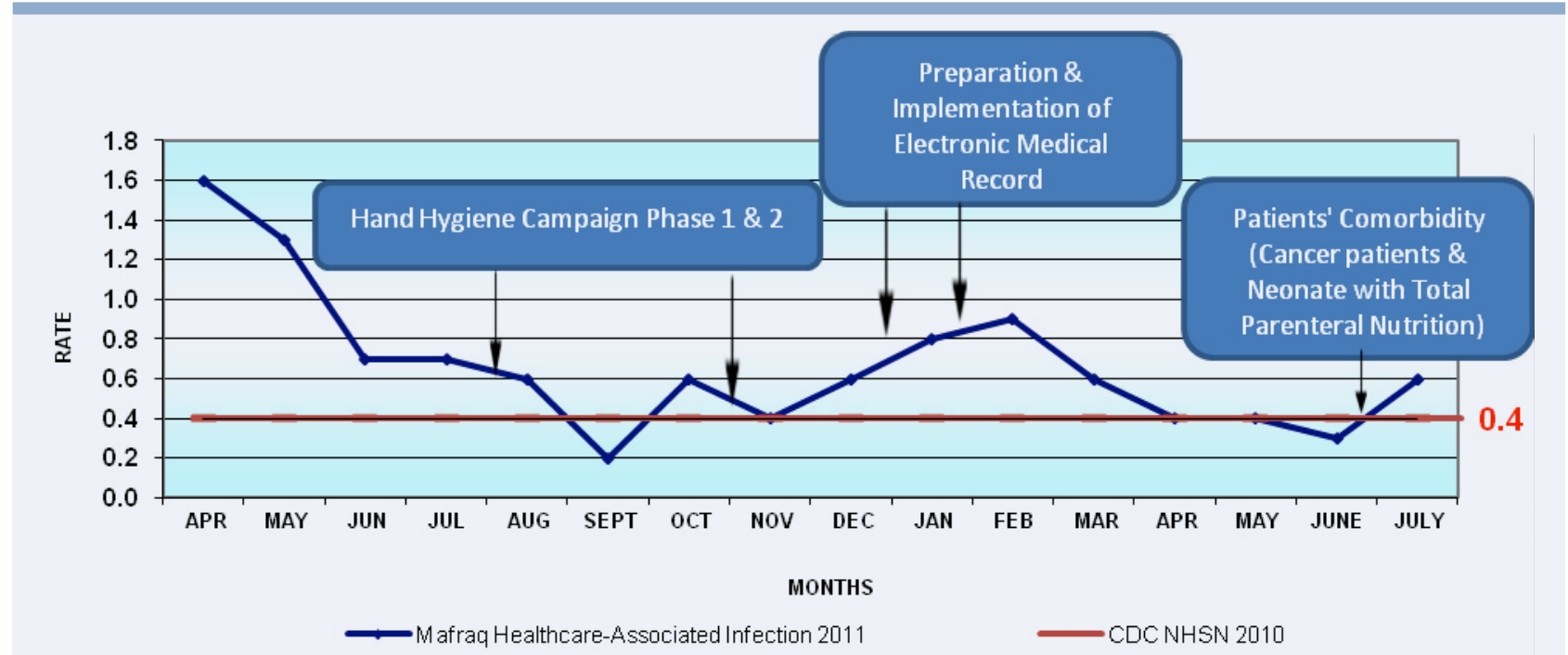

Figure 4. Mafraq Healthcare-Associated Infection April 2010 - July 2011 


\section{Discussion}

Although there have been studies showing no correlation between hand hygiene compliance and healthcare-associated infection rates or lack of scientific information demonstrating impact of improved hand hygiene on hospital infection rates, ${ }^{14}$ the evidence from the hand hygiene campaigns launched in our facility showed a decrease in healthcare-associated infections as the compliance increased.

By researching and overcoming the barriers to compliance, such as installing alcohol-based hand rub dispensers in accessible locations and posting hand hygiene posters or door hangers as reminder, Mafraq hospital has a significant increase of hand hygiene compliance by $64 \%$ in 15 months period. The significantly increased hand hygiene compliance rate to $85 \%$ in June 2011 has successfully reduced the healthcare-associated rate to 0.4 per 1000 patient days (CDC 2009 benchmark is 0.4) in April, May and June 2011 and this has aligned with the organizational goal. As for July 2011, healthcare-associated infection rates increased to 0.6 even though hand hygiene compliance rates increased to $86 \%$. However, there is nothing can be done since patient co morbidity is a non-modifiable risk factor for healthcare-associated infections. Therefore, it still can be concluded that hand hygiene compliance can be significantly improved through 'Hand Hygiene' campaigns, such as the one discussed in this paper. A limitation of this study is that since there was no result shown about patient co morbidity in the period before the hand hygiene campaigns, it is not known if the decrease of healthcare-associated infections were because of the campaigns or due to the difference in patient population.

The importance of proper hand hygiene must drive further rigorous research to explore effective interventions to change behaviour in the health care settings. ${ }^{15}$ The dynamics of behavioural change and implementation of guidelines are complex and multifaceted. It definitely involves the combination of education, motivation and system change.

\section{Acknowledgements}

Firstly, the author would like to mention that the title of this article was inspired by 'The 7 Habits of Highly Effective People' by Dr. Stephen R. Covey. ${ }^{16}$ Secondly, the author would like to thank the Director of Quality and Risk Management (Ms. Helge Springhorn) for her valuable input to this article, the infection preventionists (Ms. Reham Jafer, Ms. Prameela Maniamma and Ms. Fathia Jama Osman) and the marketing team (Ms. Amanda Banham and Ms. Salwa Ali Al Hossani) for their great efforts and help to make the campaigns successful. Last but not least, the author would also like to thank the executive team (especially Ms. Gail Smith, Chief Nursing Officer) for their support to the infection prevention and control program.

\section{References}

1. World Health Organization, 2005. WHO Guidelines on Hand Hygiene in Health Care (Advanced Draft): A Summary. World Health Organization. http://www.who.int/patientsafety/ events/05/HH_en.pdf [Accessed June 22, 2011]

2. Jarvis WR. Selected aspects of the socioeconomic impact of nosocomial infections: Morbidity, mortality, cost, and prevention. Infect Control Hosp Epidemiology 1996; 17(8): 552-557. http://dx.doi.org/10.1086/647371

3. World Health Organization (2006). WHO Guidelines on Hand Hygiene in Health Care 2006 (Advanced Draft) (1st ed.); Geneva: WHO Press.

4. Dudeck MA, Horan TC, Peterson KD, et al. National Healthcare Safety Network (NHSN) report, data summary for 2009, device-associated module. American Journal of Infection Control 2011; 39(10): 349-367. http://dx.doi. org/10.1016/j.ajic.2011.04.011

5. Helms B, Dorval S, St. Laurent P, Winter M. Improving hand hygiene compliance- a multidisciplinary approach. American Journal of Infection Control 2010; 38(7): 572-574. http:// dx.doi.org/10.1016/j.ajic.2009.08.020

6. Mah MW, Meyers G. Toward a socioethical approach to behavior change. American Journal of Infection Control 2006; 34(2): 73-79.http://dx.doi.org/10.1016/j.ajic.2005.09.004

7. Mah MW, Tam YC, Deshpande S. Social Marketing Analysis of 2 Years of Hand Hygiene Promotion. Infection Control Hospital Epidemiology 2008; 29(3): 262-270. http://dx.doi. org/10.1086/526442

8. Mah MW, Deshpande S, Rothschild ML. Social marketing: A behavior change technology for infection control. American Journal of Infection Control 2006; 34(7): 452-457. http:// dx.doi.org/10.1016/j.ajic.2005.12.015

9. Whitby M, Mclaws ML, Slater K, Tong E, Johnson B. Three successful interventions in health care workers that improve compliance with hand hygiene: Is sustained replication possible. American Journal of Infection Control 2008; 36(5): 349-355. http://dx.doi.org/10.1016/j.ajic.2007.07.016 
10. Larson E, Quiros D, Lin SX. Dissemination of the CDC's Hand Hygiene Guideline and impact on infection rates. American Journal of Infection Control 2007; 35(10): 666-675. http:// dx.doi.org/10.1016/j.ajic.2006.10.006

11. O'Boyle CA, Henly SJ, Larson E. Understanding adherence to hand hygiene recommendations: The theory of planned behavior. American Journal of Infection Control 2001; 29(6): 352-260. http://dx.doi.org/10.1067/mic.2001. 18405

12. Carrico RM, Coty MB, Goss LK, Lajoie AS. The influence of knowledge, perceptions, and beliefs, on hand hygiene practices in nursing home. American Journal of Infection Control 2009; 37(2): 164-167. http://dx.doi.org/10.1016/j. ajic.2008.04.258

13. Malekmakan L, Haghpanah S, Askarian M, Jowhari $M$, Moalaee M. Hand Hygiene in Iranian Health Care Workers. American Journal of Infection Control 2008; 36(8): 602-603. http://dx.doi.org/10.1016/j.ajic.2008.01.006

14. Pittet D. Improving Adherence to Hand Hygiene Practice: A Multidisciplinary Approach. Emerging Infectious Diseases 2001; 7(2): 234-240. http://dx.doi.org/10.3201/ eid0702.010217

15. Smith A, Carusone SC, Loeb M. Hand Hygiene Practices of Health Care Workers in Long-term Care Facilities. American Journal of Infection Control 2008; 36(7): 492-494. http:// dx.doi.org/10.1016/j.ajic.2007.11.003

16. Covey S. The Seven Habits of Highly Effective People. New York: Free Press, 2004. 